\title{
Estratégias de resistência no sistema de moradias do contexto sucroalcooleiro
}

\author{
Simone Maria Hüning \\ Aline Kelly da Silva \\ Paulo dos Santos Nascimento \\ Universidade Federal de Alagoas \\ Rondineli Bezerra Mariano \\ Universidade Federal de Juiz de Fora
}

\begin{abstract}
Resumo
Neste artigo discutimos estratégias de resistência de moradores de uma comunidade situada na propriedade de uma usina sucroalcooleira. Nesta pesquisa realizamos entrevistas não-estruturadas com moradores, roda de conversa com trabalhadores da usina, visitas à comunidade e registros em diários de campo. Utilizamos o referencial teórico de Michel Foucault para discutirmos modos de resistência e relações de poder no contexto em estudo. As principais estratégias de resistência visibilizadas relacionam-se a projetar um futuro fora da usina para as novas gerações, enfrentamentos coletivos e individuais nas situações de trabalho e constituição de redes sociais de apoio. Apesar de marcados pelas assimetrias de poder produzidas no contexto da monocultura da cana-de-açúcar, os sujeitos não se constituem como passivos diante dos modos de vida instituídos. Eles denunciam, além da violência vivida na usina, a precariedade das políticas sociais de um Estado ausente para quem vive fora dos domínios da 'segurança' oferecida nas propriedades das usinas.
\end{abstract}

Palavras-chave: processos de subjetivação; estratégias de resistência; relações de poder; setor sucroalcooleiro.

\begin{abstract}
Strategies of resistance in the housing system of the sugarcane context. In this paper we discuss strategies of resistance from residents of a community located on the property of a sugarcane industry. In this research we conducted unstructured interviews with residents, group conversation with plant workers, community visits and records in field diaries. We use the theoretical framework of Michel Foucault to discuss strategies of resistance and power relations in the context under study. The main strategies of resistance visualized relate to design a future outside the plant for future generations, collective and individual confrontations in work situations, and the constitution of social support networks. Despite these subjects are marked by asymmetries of power produced in the context of the monoculture of sugar cane, they are not passive in face of the established ways of life. Besides the violence experienced at the plant, they denounce the precariousness of social policies on an absent state for those who live outside the realm of 'safety' offered in the properties of sugarcane industry.
\end{abstract}

Keywords: subjectivation process; resistance strategies; power relations; sugarcane context.

\section{Resumen}

Estrategias de resistencia en el sistema de alojamiento del contexto de caña de azúcar. En este artículo se analizan las estrategias de resistencia de los residentes de una comunidad ubicada en la propiedad de una central azucarera. En esta investigación se realizaron entrevistas no estructuradas con los residentes, la conversación de grupo con trabajadores de la planta, visitas a la comunidad y registros en diarios de campo. Utilizamos el marco teórico de Michel Foucault para discutir las estrategias de resistencia y las relaciones de poder en el contexto estudiado. Las principales estrategias de resistencia visualizado se relacionan con el diseño de un futuro fuera de la planta para las generaciones futuras, confrontaciones colectivas e individuales en situaciones de trabajo y el establecimiento de redes de apoyo social. Aunque marcados por las asimetrías de poder que se producen en el contexto del monocultivo de la caña de azúcar, los sujetos no son pasivos ante las formas establecidas de vida. Además de la violencia que se vive en la planta, denuncian la precariedad de las políticas sociales de un estado ausente para los que viven fuera del dominio de 'seguridad' que se ofrecen en las propiedades de la central azucarera.

Palabras clave: procesos de subjetivación; estrategias de resistencia; relaciones de poder; contexto de caña de azúcar. 
$\mathrm{O}$ desenvolvimento do estado de Alagoas é marcado pela monocultura da cana-de-açúcar. Essa característica tem produzido efeitos locais que ultrapassam a dimensão econômica, especialmente se considerarmos os modos de subjetivação engendrados pelas relações construídas em torno da cultura e das usinas sucroalcooleiras. No estado destacam-se os altos investimentos na produção de conhecimentos científicos e tecnologias para fortalecimento desse setor econômico, em contraste com os precários incentivos para estudos da área das ciências humanas, sociais e da saúde, relacionados ao setor canavieiro. A configuração desse cenário nos levou ao interesse de investigar os processos de subjetivação e resistência em uma das comunidades situada na propriedade de uma usina sucroalcooleira ${ }^{1}$, localizada em um dos municípios da região metropolitana de Maceió e composta pelas famílias dos trabalhadores da respectiva usina. Tais comunidades constituem-se como vilas de trabalhadores e são caracterizadas por Albuquerque (2009) como sistema de moradias.

Nesse artigo objetivamos discutir estratégias de resistência dos moradores da comunidade e suas formas de enfrentamento aos modos de vida instituídos no contexto canavieiro, que se imprimem de forma ainda mais intensa no sistema de moradias. Assim, embora possamos afirmar que os efeitos da monocultura da cana-de-açúcar estejam capilarizados na sociedade alagoana em diversos discursos e práticas cotidianas que extrapolam aqueles que vivem diretamente relacionados a este setor (Albuquerque, 2009; Diegues Jr. 2002; Lira, 2007), ressaltamos como elemento que singularizou nosso interesse de pesquisa o fato de que a moradia, o trabalho e a vida cotidiana desses sujeitos circunscrevem-se ao território de propriedade da usina, que possui fronteiras nitidamente demarcadas. Nossa proposta relaciona-se à compreensão de que mesmo diante das assimetrias das relações nesses contextos, os sujeitos em suas práticas cotidianas produzem estratégias de resistência que recriam a possibilidade da vida confrontando as formas de governo instituídas pela e na monocultura da cana-de-açúcar. Dessa maneira, recusamos tomar tais sujeitos como dominados por um sistema econômico e de produção e, sem restringir suas vidas aos processos trabalhistas do setor sucroalcooleiro, buscamos explorar os outros vetores de subjetivação e as práticas de resistência construídas nas microrrelações na comunidade.

Para dimensionar a importância que a cultura canavieira possui no contexto alagoano podemos dizer junto com Albuquerque (2009, p. 28) que "a cana é alma das Alagoas", na medida em que sua história se confunde com a história do açúcar e sua economia é dependente da cultura canavieira. Em Alagoas, desde o período colonial a cultura de cana-de-açúcar vem sendo explorada devido às condições climáticas e solo propício da região, mas não somente por isso. A coroa portuguesa ao se dar conta de que era necessário povoar suas terras, para que ficasse realmente garantida a sua posse, tratou de oferecer pedaços de terras para alguns donatários, a fim de que estes cuidassem de vastas plantações de cana. $\mathrm{Na}$ época, o açúcar era produto de alto valor na Europa e a propriedade canavieira exigia muita força de trabalho. Assim, automaticamente o território acabaria sendo ocupado e um produto caro estaria nas mãos da metrópole (Ferlini, 2010).

Logo que se instalou como principal atividade agrícola do estado de Alagoas, a cultura canavieira já dava sinais de que seria uma monocultura e consequentemente teria como fundamento o latifúndio. Segundo Sant'ana (2011), o sistema latifundiário teve ainda mais incremento com a substituição dos engenhos e velhos banguês pelas usinas. Elas demandavam cada vez mais cana-de-açúcar, pois tinham maior capacidade de transformar a matéria prima em produtos do que os atrasados e, a partir de então, ineficientes engenhos.

A economia de base agrária capitaneada pela cana de açúcar continua hegemônica em Alagoas. Como apontou Lira (2007), a cana ocupa aproximadamente $69,3 \%$ da área cultivada no estado alagoano, sendo que sua predominância está na Zona da Mata e nos Tabuleiros Costeiros, onde está alocada a comunidade foco desta pesquisa. A importância do complexo sucroalcooleiro alagoano pode ser constatada a partir dos dados que informam que de todos os trabalhadores ligados à atividade industrial do estado, $81 \%$ estão vinculados de alguma maneira àquele setor (Lira, 2007).

Diante do quadro descrito, chamam a atenção os poucos incentivos para estudos da área das ciências humanas, sociais e da saúde, relacionados ao setor canavieiro. Além disso, as poucas avaliações sociológicas existentes poucas vezes analisam as dissimetrias sociais de Alagoas para além dos esquemas consagrados que se fundamentam na polarização entre dominantes e dominados. Tal polarização tende sempre a ressaltar a dissimetria das relações de poder, que confina os "dominados" numa posição de passividade e inatividade frente às imposições dos "dominantes".

Referendadas por relações de poder entre a pequena elite político-econômica do Estado e as maiorias populares, refletidas, sobretudo, nos péssimos indicadores sociais de Alagoas, é comum às análises sociológicas enfatizarem a ausência de resistências estruturais gestadas no interior dos meios populares, exceto aquelas que se tornaram ícones histórico-culturais como as insurreições de Zumbi dos Palmares (Freitas, 2004) e dos cabanos (Lindoso, 2005), pertencentes a um relativo passado da história de Alagoas.

Nesse trabalho, a partir de Foucault (2001), entendemos que toda relação de poder envolve a possibilidade de resistência por parte dos sujeitos nela envolvidos. Desse modo, a analítica do poder proposta por esse autor rompe com os binarismos que opõem dominantes e dominados, ao considerar que as relações de poder são justamente aquelas que permitem ao sujeito a possibilidade de resistir e lutar contra as formas de sujeição contemporâneas a ele. Entendemos, também a partir das teorizações foucaultianas, que é necessário atentar para as formas de resistência engendradas não apenas no âmbito das relações econômicas, mas também no campo das lutas contra a submissão da subjetividade (Foucault, 1995). Destacamos ainda, a compreensão foucaultiana do poder como algo produtivo, como aquilo que, na interface com saberes 
e discursos que possuem efeitos de verdade, incide sobre os sujeitos constituindo modos de subjetivação. Assim, entendemos que a própria definição desses sujeitos como dominados, por exemplo, constitui-se não apenas pelas materialidades de suas situações de vida, mas por certa configuração de saberes que incidem sobre as subjetividades e moldam isso que se produz como um modo de existência passivo.

\section{Método}

\section{Caracterização da comunidade}

A comunidade onde desenvolvemos a pesquisa é composta pelas famílias dos trabalhadores em regime efetivo da respectiva usina, que se distinguem dos trabalhadores não efetivos ou safristas. Enquanto os safristas são trabalhadores sazonais agregados à dinâmica das usinas apenas nas épocas de colheita e moenda da cana, que duram aproximadamente seis meses do ano, os efetivos possuem vínculos empregatícios perenes com as usinas.

Existindo desde a implantação da atividade canavieira na região ainda no século XIX (primeiramente como banguê e posteriormente como engenho), atualmente a comunidade é composta por cerca de 1500 pessoas, segundo informação obtida junto aos próprios moradores. Devido à presença mínima do Estado nas esferas da saúde e da educação, a maioria dos elementos ligados à sociabilidade (sobretudo os aspectos infraestruturais como gestão das moradias, condições de saneamento básico e atividades culturais) é gerenciada pela iniciativa privada representada pelos proprietários da usina em foco. A comunidade dispõe de uma escola pública de ensino médio e fundamental, um posto de saúde, um centro recreativo, um sindicato dos trabalhadores ligados à usina, um auditório público destinado a atividades culturais e cinco entidades religiosas, das quais uma é católica e quatro são protestantes.

Embora de maneira geral as reestruturações ocorridas no setor canavieiro nos últimos anos tenham sido significativas, suas repercussões sobre o regime de moradia da comunidade em foco foram poucas. A moradia na vila dos trabalhadores se dá em regime de aluguel descontado em folha nos rendimentos dos funcionários da usina. Na medida em que esses trabalhadores se desligam do complexo canavieiro, devem desocupar as casas onde residem.

\section{Estratégias de encontro}

O método pode ser definido como uma estratégia de encontro do pesquisador com seu interlocutor no processo de produção de conhecimento (Amorim, 2001). Como dispositivos para produzir estes encontros, iniciamos fazendo contato com moradores que conheciam um dos membros da equipe, nos apresentando e à proposta de pesquisa, e solicitando que esses indicassem outras pessoas com quem pudéssemos conversar a respeito. Esses primeiros contatos e visitas à comunidade foram registrados em diários de campo e, nessa oportunidade, combinamos, com aqueles que se dispuseram a participar, novos encontros para a realização de entrevistas.

Nessas entrevistas não-estruturadas buscou-se manter o caráter de diálogo abordando a vida e o cotidiano na comunidade e as mesmas foram gravadas com o consentimento dos participantes. Na realização das entrevistas participaram sempre dois ou três membros da equipe de pesquisa ${ }^{2}$, estando presentes nas conversas de um até três moradores da comunidade simultaneamente, sendo tal presença definida pelos próprios moradores, já que as mesmas realizavam-se em suas casas. Fomos autorizados pelos sujeitos ou seus responsáveis legais a gravar quatro dessas conversas, tendo a participação de cinco moradores (trabalhadores da usina, esposas dos trabalhadores e filho(a)s dos trabalhadores) que receberam nomes fictícios nesse trabalho, não sendo esse, porém, o número total de pessoas contatadas e de entrevistas realizadas. Algumas pessoas com quem conversamos dispuseram-se a falar sobre as questões propostas, porém recusaram-se à gravação, alegando preocupação com o que poderia ser feito com o material. As entrevistas autorizadas e gravadas foram transcritas na íntegra e entregues para os participantes, caso esses quisessem fazer alguma observação sobre as mesmas, porém não tivemos nenhum retorno a respeito. Os demais contatos constituem notas de campo que utilizamos para pensar as dinâmicas da comunidade. Além das entrevistas, realizamos várias visitas à vila, percorrendo seus espaços, às vezes acompanhados por moradores, buscando conhecer a estrutura e as formas de organização da comunidade.

Outra estratégia utilizada foi a realização de uma roda de conversa, que contou com a participação de cinco trabalhadores da usina que não participaram das demais entrevistas. $\mathrm{O}$ objetivo deste procedimento foi explorarmos as histórias de vida e da comunidade, os modos de relações e práticas cotidianas desses sujeitos diretamente implicados no trabalho da usina. Os registros foram feitos por anotações e diários de campo e, contando com o consentimento do grupo, o encontro foi gravado em áudio e transcrito. Os participantes dessa etapa da pesquisa foram convidados por um dos moradores da comunidade previamente contatado.

\section{Procedimentos de análise}

Nossa proposta de análise do discurso inspira-se no trabalho de Michel Foucault (1998), tomando como ponto de partida a análise do presente, introduzindo-se questões que desnaturalizam práticas de nossa sociedade atual e interrogam sobre suas condições de possibilidade (Hook \& Hüning, 2009). Na presente pesquisa, trata-se de, por um lado, situar historicamente a produção de certas subjetividades e os modos de relação a estas relacionadas, especificamente no sistema de moradia do setor canavieiro. Por outro lado, evidenciar as estratégias de resistência desses sujeitos, questionando a uma visão disseminada de dominação e apatia em relação aos mesmos. Assim, buscamos dar visibilidade à construção histórica e política dos discursos e às relações de saber e poder que perpassam a vida nesses territórios, ao mesmo tempo em que nos inscrevemos como produtores de outros discursos e, 
portanto, de outras formas de falar e produzir a vida desses sujeitos, que ultrapassam a relação econômica.

Para tanto, buscamos identificar os movimentos e acontecimentos que apontam para formas de resistência desses sujeitos frente ao instituído e, dessa maneira, dar visibilidade às modificações e rupturas dos enunciados e discursos que se configuram como formas de enfrentamento aos modos homogeneizantes de vida no contexto canavieiro. Assinala-se que, de forma convergente com o referencial teórico que norteou o estudo, buscamos nessa pesquisa a visibilidade de formas de experiência e processos de subjetivação, não em sua unidade, mas em sua multiplicidade, com suas contradições e paradoxos.

\section{Resultados e discussão}

De acordo com Foucault, a possibilidade de resistência ou, mais precisamente, de resistências (Foucault, 2001) é intrínseca às relações de poder. Esta "nunca se encontra em posição de exterioridade em relação ao poder” (Foucault, 2001, p. 91), pois, para ele, onde há poder há possibilidades de resistências. $\mathrm{O}$ autor propõe que entendamos o poder como algo capilarizado e periférico, ao invés de conceber que haja um centro de onde ele emana. Assim, Foucault diz que os poderes não se localizam em nenhum ponto específico da estrutura social, mas funcionam como uma rede de dispositivos ou mecanismos a que nada ou ninguém escapa e se exercem como uma multiplicidade de relações de forças (Machado, 1979). Essa forma de compreender as relações de poder enfatiza sua função de força produtiva de realidades, uma vez que as relações de poder estariam sempre ancoradas em discursos de verdade cuja função principal diz respeito a diferentes formas de gestão da vida. Machado (1979) aponta, nesse sentido, que Foucault estudou os modos de exercício do poder em sua articulação com o saber, considerando esse saber como peça de um dispositivo político. Dessa maneira, Foucault investigou como determinados domínios de saber - as ciências humanas, por exemplo - se formaram a partir de práticas disciplinares (Machado, 1979). Daí a afirmação de que onde há poder há também resistência: ela se produz dentro desse campo de correlações de forças, constituindo-se como "pontos móveis e transitórios que também se distribuem por toda a estrutura social" (Machado, 1979 , p. 14) e não como "um lugar da grande Recusa" (Foucault, 2001, p. 91) [grifo no original]. Por isso, é mais interessante falar em resistências, no plural (Foucault, 2001).

A resistência, portanto, na perspectiva foucaultiana, é uma multiplicidade de pontos presentes em toda a rede das relações de poder, distribuídos de modo irregular, que podem servir de adversário, de alvo, de apoio ou saliência nessas relações (Foucault, 2001). Desse modo, pode-se pensar a resistência como instrumento de luta nas relações de poder cotidianas, capaz de provocar transformações e rupturas nessas relações.

Com o desenvolvimento da indústria sucroalcooleira, que produz uma riqueza concentrada na elite alagoana, produz-se também a pobreza e a exploração de uma gama de sujeitos que enfrentam diariamente a dureza do trabalho nos canaviais e nas usinas. No entanto, acreditamos que seria simplista tomar as relações sociais que se inscrevem nos territórios usineiros meramente a partir do binarismo dominantes versus dominados, por entendermos que jamais os indivíduos são alvos inertes do poder (Foucault, 1999). Em qualquer rede de poder onde se travam lutas entre indivíduos livres (ainda que se possa discutir o que seja essa liberdade) há a possibilidade de criar resistências, que não são exteriores ou externas ao poder, mas são engendradas dentro das próprias tramas onde ele transita pelos indivíduos (Foucault, 1999).

Situaremos aqui aquilo que consideramos como principais estratégias de resistência diante das formas como o poder se apresenta nas relações cotidianas na comunidade onde desenvolvemos a pesquisa. Compreendemos que tais estratégias englobam movimentos de recusa a certas formas de governo, a capacidade de formular uma crítica ao exercício do poder, ainda que circunscrita ao campo de possibilidades desses sujeitos. Nesse sentido, Branco (2001, p. 246) argumenta que as lutas de resistência exigem "um trabalho contínuo e sem descanso de afrontamento dos processos de autonomização contra as técnicas de individuação e normalização" e defende que é necessário "produzir, criar, inventar novos modos de subjetividade, novos estilos de vida, novos vínculos e laços comunitários, para além das formas de vida empobrecidas e individualistas implantadas pelas modernas técnicas e relações de poder" (Branco, 2001, p. 246).

Antes, porém, destacamos que neste contexto específico, a própria organização física da comunidade dentro do território que é propriedade da usina opera como aquele que nos parece ser o mais importante mecanismo e normalização que tem por alvo os corpos dos indivíduos e suas condutas. Esse aspecto merece destaque, pois a vida dessas pessoas, para muito além do espaço e do tempo do trabalho, é vivida "na usina", como eles referem. Para mencionar apenas algumas das medidas de disciplinarização que compõem a estratégia de governo e normalização na comunidade, além do controle do principal acesso à comunidade através de uma guarita vigiada, há toda uma organização espacial e humana, que divide as casas em diferentes setores conforme a posição dos trabalhadores na empresa. Há ainda a limitação de espaços acessíveis ou não a determinadas pessoas e de atividades que podem ser realizadas "na usina", com a limitação de festividades e a extinção dos bares, embora outras atividades comerciais sejam permitidas.

Para pensarmos essas estratégias no contexto da comunidade em questão iniciamos pelo modo como, principalmente os mais jovens, projetam, com o incentivo de seus pais, a saída da vila, principalmente em busca de estudo e melhores condições de trabalho:

Não quero trabalhar aqui na [usina], eu estou fazendo curso, tentando me aperfeiçoar pra sair daqui, que eu não gosto muito daqui, não (...) Poucos que continuam aqui... Que tiveram acesso, né, a outras coisas, aí gostariam de sair daqui... São poucos que continuam (Leila, 17 anos).

Para a jovem, a recusa pelo modo de vida instituído nesse território também perpassa a vontade de passar pouco tempo 
no local em que mora, ao relatar que na maior parte de seu tempo livre busca estar em locais fora da "usina" (os moradores da comunidade referem-se à comunidade como usina: moram na usina, trabalham na usina, estudam na usina, frequentam a igreja na usina, entre outros.).

Leila nasceu e passou toda a sua vida na usina. Frequentou a escola local até o ensino fundamental e participa ativamente das atividades religiosas de uma das igrejas da vila, de modo que suas experiências de vida constituíram-se de modo bastante conectado com esse espaço físico. Mas embora Leila considere o local calmo e tranquilo (definição unânime entre os moradores com quem conversamos), deixa claro que não planeja a continuidade de sua vida aí, destacando que a essa tranquilidade sobrepõem-se à escassez de opções de lazer, a dificuldade de acesso à internet e a meios de transporte e serviços básicos.

De forma bastante frequente, a saída da comunidade, quando pode ser planejada e não compulsória (como pelo rompimento do vínculo de trabalho com a usina, seja por demissão ou aposentadoria), é vista como uma possibilidade de mudança e ruptura com aquilo que é considerado mais difícil na vida na comunidade: trabalho digno, falta de opções de lazer e de vida, privações financeiras e de oportunidades, dificuldades de mobilidade, restrição da autonomia. Projetar um futuro diferente da vida na usina passa por sua busca por morar e estudar fora da comunidade, projeto compartilhado por pais e filhos.

Joana: Assim, a vida aqui é boa pra quem não gosta de movimento, de multidão, né... Pra quem quer crescer na vida aqui não tem futuro não. É boa pra mim porque não tem mais jeito mesmo... Não acho que seja bom começar aqui não.

Pesquisadora: Não é um lugar pra começar?

Joana: Não. Não tem futuro. Eu acho que é um lugar pra quem quer tranquilidade. Mas pra quem tem assim um sonho de estudar e crescer, aqui não. Eu não indico (Joana, 47 anos).

As pessoas mais velhas procuram proporcionar aos seus filhos um futuro diferente da vida marcada pelos sofrimentos aos quais foram submetidos durante o trabalho com a canade-açúcar na infância - principalmente com o corte da cana - e na usina durante a vida adulta: "Eu sempre queria dar uma vida melhor pros meus filhos... o que eu não tive. Aí eu me esforcei, paguei o curso dele (...)." (Joana, 47 anos). Nessa e nas demais entrevistas, projetos de estudo, trabalho e crescimento são sempre remetidos para fora do contexto da comunidade e da usina, desvinculados do local de moradia e trabalho atual. Em nenhum dos contatos que tivemos foram relatadas expectativas ou planos de uma melhoria nas condições profissionais ou de vida na própria usina, o que nos informa sobre a clara insatisfação das pessoas com sua condição de vida atual, bem como sobre sua luta cotidiana para modificá-la (quase sempre investida nas gerações mais jovens, diante de uma ausência de perspectivas de que tais mudanças possam ocorrem em suas próprias vidas), não se curvando àquilo que poderia ser tomado como um destino já dado para estes sujeitos.
Quando nos aproximamos das relações de trabalho relatadas pelos homens trabalhadores da usina, nos deparamos com inúmeras situações de violência (física e simbólica) cotidianas exercidas sobre os trabalhadores. Pudemos, ainda assim, identificar formas de enfrentamento, individuais e coletivas, dos trabalhadores de diferentes posições hierárquicas.

Além da busca por organização sindical (que os trabalhadores analisam como limitada em função da configuração política do estado e das relações de políticos e autoridades com os usineiros) são acionadas estratégias individuais de enfrentamento do cotidiano e das chefias de setores. Decepcionado com a exploração trabalhista e o tratamento dispensado a ele e aos demais colegas após anos de serviço em um setor da usina, João relata que uma forma de lidar com as cobranças e explorações que se tornaram insuportáveis (a ponto de desencadear-lhe Distúrbio Osteomuscular Relacionado ao Trabalho (DORT) e depressão) consiste em confrontar seus superiores hierárquicos em relação aos seus direitos como trabalhador e como ser humano. Relata já ter discutido várias vezes com os encarregados do setor onde trabalha e critica especificamente o setor de Recursos Humanos e os técnicos de segurança do trabalho.

$\mathrm{E}$, assim, tem recursos humanos na usina, tem segurança do trabalho, tem medicina do trabalho, mas tudo é um grupo ali, né, é um grupo que faz o que o dono manda, não é verdade? Eu já cheguei a falar na cara de alguns lá, encarregados. Eles querem vir, assim, botar moral, falar coisa que eu não gosto, eu abri a boca pra ele, eu não ficava por baixo não. Eu mandava ele me respeitar (...) (João, aproximadamente 50 anos).

João denuncia também a ausência de equipamentos adequados para a proteção dos trabalhadores. Conta, de forma impactante, sobre a morte de colegas em decorrência de acidentes de trabalho resultantes da falta de fornecimento de equipamentos por parte da usina. A indignação dos trabalhadores ao relatarem seu cotidiano de trabalho não apenas evidencia seu inconformismo com as condições a que são submetidos, como também nos lembra a precariedade das relações trabalhistas no setor sucroalcooleiro do estado.

Se tal configuração pode ser em grande parte atribuída ao desenvolvimento da monocultura da cana e das relações de escravidão desde os banguês, no contexto atual vemos somar-se a essa 'tradição' práticas modernas de gestão de pessoas que contribuem para a definição dos modos de governo da vida nesses espaços. Particularmente nos chamou a atenção a crítica formulada por João a práticas da psicologia, utilizadas no contexto de trabalho, relatando uma situação vivida com uma psicóloga, após a mesma ter proferido uma palestra na usina sobre comportamento adequado em uma empresa:

O que a senhora está dando aqui aos peões, chamasse o presidente da empresa pra começar dele, vir até a liderança dele, pra você ter a conversa que teve com a gente. Porque essa palavra que a senhora está falando, isso que a senhora está dizendo pra mim, esses daqui, a gente já faz isso de cor e salteado (...). Eu disse: "olhe, a senhora deveria chamar o presidente e as lideranças dele e conversar isso. Porque isso: eles deveriam tratar a gente desse jeito que a senhora está dizendo. Eles que deveriam tratar bem os trabalhadores, está entendendo? Porque nós já somos ovelha até demais. Nós não somos trabalhadores não, nós somos ovelhas ali dentro da empresa” (...). (João). 
O relato de João não deixa dúvidas sobre a utilização de técnicas psicológicas para a promoção de adaptação e ajustamento dos trabalhadores da usina, numa clara referência aos modos como o exercício do poder se articula a formas de saber. No entanto, nota-se a recusa do trabalhador, sugerindo que esse discurso seja endereçado aos encarregados, gerentes, chefes, enfim, aos líderes de quem partem as agressões diárias contra os trabalhadores. João começou a falar sobre a vida e o trabalho na usina sem que fizéssemos qualquer pergunta. Ele já esperava por nossa visita, que havia sido informada pela esposa. Apenas nos apresentamos, ele começou a falar e o interrompemos para solicitar as autorizações formais. Feito isso, o trabalhador retomou sua narrativa que só foi interrompida aproximadamente duas horas depois, com a chegada de um carro que parou em frente a sua casa, que nós pesquisadores não identificamos, nos levando a encerrar a entrevista. João assume uma postura de coragem, enfrentamento e denúncia das situações de humilhação e desrespeito vivenciadas principalmente no cotidiano de trabalho na usina. Atualmente, João sofre com problemas de saúde decorrentes de sua atividade profissional e não se sente amparado pela empresa. Seu relato é impactante:

Chegou um momento que eu fiquei com um desespero tão grande que eu achava que eu iria me explodir, está entendendo? Aquela angústia, aquela agonia, aquele desespero que... Às vez (sic) eu entrava aqui nesse quarto aqui, colocava dois travesseiro no meu ouvido pra não ouvir ninguém falar, porque tudo que o povo falava me ofendia. O que o povo falava dava angústia em mim, entendeu? E, resumindo, né, e tem vez que eu não posso falar que eu fico um pouco emocionado, né? Teve um momento que deu vontade de chegar lá usina e discutir, quebrar máquina, pra me vingar do que eu estava passando (João).

É importante notar que pela sua ocupação profissional, dentre os entrevistados, João é quem mais está submetido à força do poder e é também quem mais traz aspectos de resistência. Nesse sentido, Foucault (2010a) afirma que o ponto onde as vidas se chocam e se debatem com o poder é justamente o mais intenso, aquele em que se concentra a energia de quem tenta escapar das armadilhas do poder. Já que as relações de poder abrem possibilidades reais de resistência, o poder de quem domina tenta manter-se com mais força quanto maior for a resistência (Foucault, 2010b) e vice-versa: quanto mais atravessado e subjugado pelas dissimetrias do poder, mais necessário será ao sujeito produzir enfrentamentos, estratégias de resistência que lhe permitam sair do assujeitamento.

João, que falou conosco praticamente por duas horas sem que precisássemos fazer perguntas, corporifica a revolta de um trabalhador que foi tratado como se fosse máquina no cotidiano de trabalho da usina. Em decorrência dos esforços exaustivos em sua rotina laboral, veio o adoecimento físico e, após passar por um processo de negligência de seus direitos trabalhistas diante do DORT, de insinuações de que estaria "enrolando" para não trabalhar, da negação de um sofrimento anterior, veio o atual adoecimento, sob o diagnóstico de depressão.

Os relatos dos moradores e trabalhadores entrevistados nos permitem acompanhar as transformações ocorridas na usina ao longo dos anos e sua relação com as mais recentes configurações do capitalismo neoliberal, calcado na flexibili- zação das relações de trabalho e na culpabilização individual (Bauman, 2001) por prováveis fracassos ou sucessos. No contexto usineiro, de acordo com Plancherel, Albuquerque e Melo (2007), os proprietários de usinas, antes nomeados de usineiros, buscam reafirmar-se atualmente sob uma nova identidade social: empresários ou industriais. Uma das implicações disso é que, a partir de então, não haveria, supostamente, patrões que oprimem e trabalhadores que são explorados, mas sim "colaboradores" que precisam gerar a produtividade exigida pelos interesses do capital, se não quiserem ser descartados, por "fraqueza" individual.

$\mathrm{Na}$ roda de conversa realizada, as condições de trabalho e suas transformações também ganharam destaque. Nessa, foi destacada a existência de uma organização sindical dos trabalhadores que mantém vivo o questionamento e a pauta dos direitos e do respeito ao trabalhador. Porém, os próprios trabalhadores expressaram que, muitas vezes, se sentem impotentes diante dos principais atores da política institucional local (usineiros, políticos).

Em relação a esse aspecto, Albuquerque (2009), ao estudar contexto semelhante ao que aqui exploramos, atribui a ausência de maior articulação política coletiva ao uso da violência empregada para reprimir aqueles que denunciam e, concomitantemente, silenciar também outros trabalhadores antes mesmo que eles tentem ingressar na Justiça do Trabalho, a fim de cobrar os direitos. Tal análise, que consideramos pertinente também ao nosso contexto de pesquisa, atribui ainda maior significância à existência do sindicato local. Parece-nos que o sindicato tem produzido efeitos importantes de resistência, dada a forma como o questionamento dos direitos trabalhistas foi recorrente nas conversas realizadas:

Assim, eu não gostaria de sair, mas se acontecer, eu só saio quando pagarem o último centavo dele [do esposo]. Porque assim, a gente põe na justiça... A gente tem que saber como fazer, porque você não vai assim... Uma vida... Ele tá com quase 40 anos aqui, e você sair de uma firma e não ter nem o dinheiro de comprar nem uma casa?! Fica difícil, né? (Joana).

O apoio social entre os moradores foi outro aspecto que se destacou em todos os contatos realizados com os participantes da pesquisa e que compreendemos como uma importante estratégia de enfrentamento aos modos de vida instituídos e às dificuldades enfrentadas no cotidiano. Em mais de uma situação de pesquisa, fomos informados de que há na comunidade um suporte social efetivo com relações de cooperação entre as famílias dos trabalhadores. Para além de situações em que, se faltar açúcar, pode-se recorrer a um conhecido mais próximo, ouvimos relatos de que essa ajuda se estende às questões de saúde: se alguém adoecer e precisar se deslocar para fora da usina, algum vizinho ou parente que possua carro é chamado para prestar auxílio no transporte. Carlos (47 anos) ratificou a existência desse apoio social ao contar que durante sua infância não passou fome devido à ajuda que sua família recebeu de moradores e considera que "a coisa muito importante por aqui é a amizade do povo" (Carlos). É Carlos também quem relata haver na comunidade um grupo organizado de pessoas, espécie de associação ou união, ressaltando a importância do coletivo: 
Pesquisador: Sabe me dizer se aqui em [usina] tem associação de moradores?

Carlos: Olha, isso é uma coisa muito importante. (...) $\mathrm{Na}$ [nome da rua localizada na usina] tem.

Pesquisador: E o que é que a associação faz?

Carlos: Não é nem associação, é quase uma união lá. Fizeram uma casinha lá, tem um barzinho. Quando eles querem comemorar alguma coisa, comemoram. Esse cara pegou um Fiat botou lá, na associação de lá. Qualquer pessoa que se sente doente, qualquer coisa, pega o carro (Carlos).

No choro de Joana, que embarga sua voz ao ser perguntada sobre a infância de trabalho no canavial; no olhar e na indignação do tom de voz de João, ao falar sobre as ocasiões em que entrou no banheiro para chorar e sobre a impotência sentida diante de uma lesão muscular seguida de depressão, que o impossibilitaram de continuar trabalhando, entram em cena afetos que tensionam o que talvez suas palavras não consigam expressar. É isso que pode ser registrado a partir de suas histórias: a afetividade como elemento presente na produção de territórios de existência (Bomfim, 2009).

Nas estratégias de encontro com as pessoas que participaram dessa pesquisa e ao tomarmos suas narrativas como 'materiais de análise', consideramos que o discurso não trata somente da manifestação de um sujeito, pois o sujeito da linguagem "é ao mesmo tempo falante e falado, porque através dele outros ditos se dizem” (Fischer, 2001, p. 207). Desse modo, é possível afirmar que as pessoas com quem conversamos não falam somente de si, não se trata de um simples ato de fala individual, mas de práticas que as constituíram no decorrer da vida: destituição de lugar, restrição da autonomia, desesperança de que algo possa mudar, coragem de denunciar certas situações, indignação, revolta, que perpassam os processos de subjetivação e as estratégias de resistências das pessoas dessa comunidade.

\section{Considerações finais}

Nosso objetivo em buscar tais narrativas e apresentá-las tornando visíveis as experiências de vida dos participantes não foi o de interpretar ou descobrir sentidos supostamente ocultos nas palavras, mas evidenciar formas de enfrentamento aos modos de vida instituídos. Interessou-nos ainda explicitar o modo como o discurso é efeito e, ao mesmo tempo, instrumento de lutas, aquilo pelo qual se luta em nossa sociedade (Foucault, 1998), na medida em que estabelece e sustenta determinados regimes de verdade, que nos produzem como sujeitos. Dar visibilidade às experiências desses sujeitos é fazer aquilo a que nos convida o próprio Foucault (1999): reativar saberes sujeitados, dar lugar aos discursos "marginais" e colocá-los em confronto com discursos unitários e homogeneizantes.

As práticas de resistência produzidas por esses sujeitos constituem-se como possibilidades de criação de modos de vida alternativos aos já instituídos no contexto canavieiro, como lutas que se travam não apenas no campo econômico, mas também no que diz respeito ao campo das subjetividades, à invenção de outros modos de viver e se relacionar com o mundo. A resistência, nesse sentido, é sempre aquilo que escapa ao instituído, a determinados saberes e poderes que se exercem sobre o indivíduo. As experiências de vida narradas pelas pessoas com quem conversamos mostram as inquietações em relação às condições de vida no local.

Diante dessas experiências, mesmo com as impressionantes condições de violência vividas pelos moradores, bem como as assimetrias das relações de poder nesse território, pudemos identificar formas de resistência em relação tanto ao contexto de violência no âmbito do trabalho e seus direitos, como em relação a outros aspectos da comunidade como a precária assistência em saúde, dificuldade de locomoção para a cidade, dificuldades econômicas etc. As diferentes narrativas compartilhadas reafirmam a potência de vida e suas múltiplas formas de expressão: projetos de vida fora da usina, recusas possíveis no campo do trabalho, redes de apoio social etc. As estratégias de resistência aqui pontuadas certamente não encerram as formas desses sujeitos enfrentarem as relações de poder estabelecidas e estão circunscritas ao que foi possível acessar, como pesquisadores, diante do rigoroso controle de entrada na comunidade que limitou nosso acesso às pessoas e ao seu cotidiano.

As narrativas com que tomamos contato no processo da pesquisa nos fizeram inicialmente perceber que algumas questões que poderiam parecer para nós, sujeitos alheios ao contexto estudado e produzidos em uma realidade bastante diferente da dessas pessoas, como atitudes de absoluta submissão, envolvem cálculos a partir das formas de se relacionar com a realidade. Tal avaliação parece, às vezes, coincidir com a avaliação que fazem os moradores, quando apreciam suas condições de vida na comunidade comparadas àquilo que poderiam encontrar no "mundo lá fora". Não é a toa que falam de um perigo ou do medo da violência "lá fora", uma nova forma de violência, já que a saída da usina quase sempre representa a mudança para regiões periféricas que, por sua vez, também oferecem poucas condições de estrutura, onde o Estado é tão ou mais ausente que na propriedade particular.

Compreendemos que essas pessoas têm gerido suas vidas de acordo com as possibilidades que consideram adequadas a partir de um universo de escolhas possíveis, e, na medida em que essas possibilidades tornam-se mais concretas para eles próprios, tecem resistências cotidianas. Resistências que não estão relacionadas a bandeiras político-partidárias nem a grandes movimentos históricos, mas que acontecem em um plano "micro", engendrando rupturas no cotidiano, ou, usando as palavras de VeigaNeto (2003, p. 26), provocando as "pequenas revoltas diárias”, sobretudo no campo das lutas que Foucault (1995) denominou de lutas contra a submissão da subjetividade. Assim, ainda que consideremos relevantes os estudos nas ciências sociais cujas análises voltam-se à subordinação e à sujeição que caracterizam o sistema de vilas de moradias, faz-se necessário lançar um olhar atento sobre as formas 
de resistência do cotidiano, os "pequenos enfrentamentos, microlutas, de algum modo” (Foucault, 2010b, p. 231), sejam quais forem, produzidos nesse contexto, a fim de potencializá -los bem como produzir instrumentos "de ação política e de intervenção política sobre a realidade que nos é contemporânea e sobre nós mesmos" (Foucault, 2010b, p. 240). Nosso intuito foi precisamente este: dar visibilidade às formas de resistência que, mesmo às vezes despercebidas, têm a potencialidade de transformação e (re)criação de modos de viver.

Cabe também a nós criarmos espaços de resistência, pois esse é um dos desafios para a psicologia contemporânea (Nardi \& Silva, 2004). Se a linguagem é um instrumento de manutenção de certas relações de poder que produzem assujeitamento, ela é também "um importante instrumento de afirmação das resistências e dos anseios de libertação" (Albuquerque, 2009, p. 23). E, nesse sentido, a própria atividade de pesquisa, ao interrogar os moradores pautando uma reflexão sobre a vida na usina, dispara movimentos de transformação e criação de outros modos de vida como formas de enfrentamento aos processos de homogeneização da vida no contexto canavieiro. A possibilidade de falar, refletir e objetivar situações cotidianas não apenas com os pesquisadores, mas com outros moradores, como na roda de conversa, o surgimento dos tensionamentos produzidos pelo medo e seu enfrentamento compõem dispositivos para a produção de novas formas de significar a si e de resistir.

Quando nos falam que o mundo da usina é mais seguro do que o "mundo lá fora", o que se denuncia não é apenas uma condição dessa comunidade, mas é também um Estado que se faz ausente para aqueles que ousarem viver suas vidas para além dos domínios da 'segurança' oferecida na propriedade das usinas, sob a proteção e comando dos usineiros. Tanto esses movimentos, como também as formas de violência e opressão engendradas por esse sistema cultural, político e econômico secular de Alagoas, precisam ser mais visibilizados e até mesmo denunciados, função política que buscamos cumprir com essa pesquisa. É a partir disso que podem ser mobilizadas, não apenas pelos próprios sujeitos, mas por setores competentes do Estado, formas de intervenção e apoio que amparem, encorajem e suportem uma mudança nas condições de vida dessas pessoas, cuja posição de fragilidade no campo social é proveniente da própria história de nossa colonização e dos caminhos tomados para o desenvolvimento econômico do estado, desvinculados do seu desenvolvimento social.

\section{Referências}

Albuquerque, C. F. (2009). Cana, casa e poder. Maceió: EDUFAL.

Amorim, M. (2001). O pesquisador e seu outro. São Paulo: Musa Editora.

Bauman, Z. (2001). Modernidade líquida. Rio de Janeiro: Jorge Zahar.

Bomfim, Z. A. C. (2009). Cidade e afetividade como categorias de mediação na psicologia social e na psicologia ambiental. In J. Bernardes \& B. Medrado (Orgs.), Psicologia social e politicas de existência: fronteiras e conflitos (pp. 163-173). Maceió: ABRAPSO.

Branco, G. C. (2001). As resistências ao poder em Michel Foucault. Transformação, 24(1), 237-248. doi: 10.1590/S0101-31732001000100016
Diegues Jr., M. (2002). O bangüê das Alagoas: Traços da influência do sistema econômico do engenho de açúcar na vida e na cultura regional. Maceió: EDUFAL.

Ferlini, V. L. A. (2010). Açúcar e colonização. São Paulo: Alameda.

Fischer, R. M. B. (2001). Foucault e a análise do discurso em educação. Cadernos de Pesquisa, 114, 197-223. Recuperado de http://www.scielo.br/pdf/cp/ n114/a09n114.pdf

Foucault, M. (1995). O sujeito e o poder. In H. L. Dreyfus \& P. Rabinow (Orgs.), Michel Foucault, uma trajetória filosófica: Para além do estruturalismo e da hermenêutica (pp. 231-249). Rio de Janeiro: Forense Universitária.

Foucault, M. (1998). A ordem do discurso. (4⿳⺈-a ed.). São Paulo: Edições Loyola.

Foucault, M. (1999). Em defesa da sociedade: Curso no Collège de France (19751976). São Paulo: Martins Fontes.

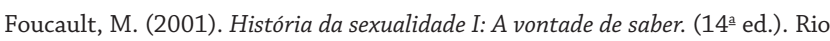
de Janeiro: Edições Graal.

Foucault, M. (2010a). A vida dos homens infames. In M. Foucault (Org.), Estratégia, poder-saber - ditos e escritos IV (pp. 203-222). (2ª ed.). Rio de Janeiro: Forense Universitária.

Foucault, M. (2010b) Poder e saber. In M. Foucault (Org.), Estratégia, podersaber - ditos e escritos IV (pp. 223-240). (2 ${ }^{\underline{a}}$ ed.). Rio de Janeiro: Forense Universitária.

Freitas, D. (2004). A república dos Palmares: Pesquisa e comentários a documentos históricos do século XVII. Maceió: EDUFAL.

Hook, D., \& Hüning, S. M. (2009). Genealogia, contra-saberes e psicologia. In N. M. F. Guareschi \& S. M. Hüning (Orgs.), Foucault e a Psicologia. ( $2^{\mathrm{a}}$ ed.). Porto Alegre: EDIPUCRS.

Lindoso, D. (2005). A utopia armada: Rebeliões de pobres nas matas do Tombo Real. (2aed.). Maceió: EDUFAL

Lira, F. (2007). A formação da riqueza e da pobreza de Alagoas. Maceió: EDUFAL.

Machado, R. (1979). Por uma genealogia do poder. In M. Foucault (Org.), Microfísica do poder (pp. 7-22). Rio de Janeiro: Edições Graal.

Nardi, H. C., \& Silva, R. N. (2004). A emergência de um saber psicológico e as políticas de individualização. Educação \& Realidade, 29(1), 187198. Recuperado de http://seer.ufrgs.br/educacaoerealidade/article/ view/25425

Plancherel, A. A., Albuquerque, C. F., \& Melo, S. R. G. S. (2007). Trabalho na agroindústria açucareira de Alagoas. Latitude, 1(2), 119-134. Recuperado de http://www.seer.ufal.br/index.php/latitude/article/view/81

Sant'ana, M. M. (2011). Contribuição à história do açúcar em Alagoas. Maceió: Cepal.

Veiga-Neto, A. (2003). Foucault \& a Educação. Belo Horizonte: Autêntica. 


\section{Notas}

1. A pesquisa "Processos de subjetivação e resistência no contexto da monocultura da cana-de-açúcar em Alagoas" foi desenvolvida entre os anos de 2010 e 2012, com financiamento do Edital Universal CNPq. 2. A equipe foi composta pela coordenadora da pesquisa e três bolsistas de iniciação científica do Curso de Psicologia da UFAL.

Simone Maria Hüning, Doutora em Psicologia pela PUCRS e Pós-Doutoranda no Brazil Institute, Kings College London, é Professora Adjunta III do Instituto de Psicologia, Universidade Federal de Alagoas (UFAL). Endereço para correspondência: Rua Prefeito Abdon Arroxelas, 853 apto 502, Ponta Verde, Maceió - AL. CEP: 57035-380. Telefone (UFAL): (82) 3214-1786. E-mail: simonehuning@yahoo.com.br

Aline Kelly da Silva, graduada em Psicologia pela UFAL, é Mestranda em Psicologia pela Universidade Federal de Alagoas (UFAL). E-mail: kelly_legiao@hotmail.com

Paulo dos Santos Nascimento, Mestre em Psicologia pela UFAL, é Professor Substituto do curso de Psicologia da Universidade Federal de Alagoas (UFAL). E-mail: prteologo@hotmail.com

Rondineli Bezerra Mariano, graduado em Psicologia pela UFAL, é Mestrando em Psicologia pela Universidade Federal de Juiz de Fora (UFJF). E-mail: rondineligtr@hotmail.com 